\title{
Differentiation of Population Incomes in Russian Arctic Regions
}

\author{
Olga Potasheva1, Marina Moroshkina,", and Gennadii Gienko² \\ ${ }^{1}$ Institute of Economics, Karelian Research Centre, Russian Academy of Sciences \\ ${ }^{2}$ Institute of Economics and Law, Petrozavodsk State University \\ ORCID \\ Marina Moroshkina: 0000-0001-6520-4248
}

\begin{abstract}
This research analyzed the factors influencing the differentiation of income in regions of the Russian Arctic zone. The demographic indicators of the trends in human capital were analyzed, namely the distribution of workers in the economy by educational level, the number of university students, and the population younger than working age. Based on the data obtained, groups of regions were identified according to per capita income growth and its dependence on level of education. The aim was to study the dynamics of household income growth in the Arctic regions, examine the conditions for the formation of a group with a higher education level, and determine the specifics of the factors influencing these indicators. The results showed that there can be no single solution for regional problems of economic development across the Arctic. In the process of planning and programming the development of this macroregion, one should take into account the specific characteristics of autonomous districts and groups of regions with their unique, historically formed, development tasks.
\end{abstract}

Corresponding Author:

Moroshkina Marina Valeryevna; email: maribel@mail.ru

Published: 11 February 2022

Publishing services provided by Knowledge E

(c) authors. This article is

distributed under the terms of the Creative Commons

Attribution License, which

permits unrestricted use and redistribution provided that the original author and source are credited.

Selection and Peer-review under the responsibility of the KarRC Conference Committee.

\section{G OPEN ACCESS}

Keywords: income, differentiation, region, education, population

\section{Introduction}

In modern conditions, the economic development of regions is characterized by a high level of heterogeneity, both in territorial terms and in indicative characteristics. Research aimed at assessing and analyzing the indicators of this process emphasizes the importance of the scientific problem of determining the degree of differentiation of Russian regions, identifying patterns, developing management decisions that can be used in strategic and territorial planning.

The issue of the level of income differentiation in Russia currently remains one of the most debatable. The dynamics of the population's income determines the socioeconomic orientation of the region's economy and is one of the key indicators of the well-being of its society, determining the public demand for the development of the social services sector and the formation of conditions for the development of the human potential. According to the study "Region Rating by Population Income 2020," conducted by experts of the RIA agency [1], the most financially prosperous 
regions of Russia in 2019 were the Nenets and Yamalo-Nenets Autonomous Districts. It should be noted that territories of the Arctic macroregion, which includes fully or partially the following constituent entities of the Russian Federation - Komi Republic, Republic of Sakha (Yakutia), Krasnoyarsk Krai, Arkhangelsk and Murmansk Regions, Nenets, Yamalo-Nenets, Chukotka Autonomous Districts and, since 2017, the Republic of Karelia, occupy a special position in the regional study of social and economic factors. Stimulation of economic development, implementation of the federal development program for the Arctic zone of the Russian Federation on the basis of "support zones," implementing state projects and programs for the development of the transport and logistics system and infrastructure [2] - all this contributed to the economic growth of these regions.

The current stage of development of Arctic regions is characterized by peculiarities noted by scientists in their studies of the Arctic: sane distribution of production capacities, organization of economic and production activities [3], as well as efficient use of the resource potential (human, natural, production, and technical) within the boundaries of this macroregion [4]. The factors influencing the economic development of the Arctic regions have a significant number of indicators - GRP, per capita GRP, industrial development, employment and unemployment, economic structure, development of the banking and financial sector, etc. On the one hand, the peculiar economic and geographical location of these regions opens the economic potential for development - the possibilities of foreign economic and cross-border relations, the possibilities of innovative development of the production sector [5], actualization of the human potential [6]. On the other hand, the natural and climatic characteristics impose restrictions on the development of certain sectors of the economy [7].

Currently, the Arctic zone accounts for $28 \%$ of the entire territory of Russia, but the its share of the permanent resident population is only $1.66 \%$ of the total population of the country. This situation is due to both the historically prevailing conditions for the development of the Russian North and the worsening situation of differentiation in money incomes [8]. According to Russian official statistics, the average per capita income in the Arctic is 1.2-2.4 times higher than in Russia as a whole. Calculations by the Russian Ministry of Economic Development show that in recent years, wages have made the greatest contribution to the growth of per capita population incomes in regions of the Arctic zone.

At the same time, the effects of changes in the labor market are evident. Today, specialists of a fundamentally new level, mainly with higher level of education, are required for the development of the Arctic economy. The existing educational potential 
of the population of the Arctic regions cannot fully meet the need for human resources [9]. Those who come to work from other Russian regions on a rotational basis cover only $30 \%$ of the need for personnel [8].

What makes this research relevant is that is studies the current difficult situation of imbalance in the socio-economic development of regions of the Russian Arctic. Young people continue migrating out of the regions, although there has been a tendency for the growth of population incomes due to an increase in the share of wages. The economy's demand for highly qualified personnel and mid-level specialists, including skilled workers and employees, is growing, but the current solution is the increasing replacement of the existing labor force with flows of labor migration from other Russian regions.

The purpose of the work is to study the dynamics of population income growth and the conditions for the formation of a population group with a higher level of education, to determine the specifics of the factors that affect these indicators.

\section{Methods and Equipment}

Studies of regional differentiation can be found in papers by foreign and Russian scientists, in which economic and social indicators are estimated on the basis of fundamental approaches to estimating key indicators suggested by K. Gini, A. Teil, E. B. Atkinson [10, $11,12]$. As part of the analysis of regional inequality, various indicators are considered. To study regional practices, it is interesting to estimate the regional stratification of the population in terms of average per capita income [13]. Regional inequality is estimated here by calculating the coefficient of variation [14], and the indices of spatial stratification: Teil [11], Herfindahl-Hirschman [12].

The problem of income differentiation is widely discussed in the works of Russian scientists [15]. A study of the problem of differentiation of the population by the level of material wealth is presented in a paper of Gordievich and Ruzanov [16], where it is reflected in the distribution of the population by the average per capita money income.

The optimal level of differentiation of population incomes, first of all, average salaries in the Arctic zone, is substantiated in a paper by Gataullin [17]. The proposed approach identifies groups of workers and takes into account the qualifications of workers, the specifics of the type of work and shows that salaries increase depending on the education level of the workers.

A study by Korchak [18] focuses on the issue of estimating the poverty level of the population in northern and Arctic regions. Analyzing the indicators of average per 
capita income, average monthly salaries, other indicators of poverty of the 'families with children' population group, the author emphasizes the threat of the appearance and aggravation of long-term negative trends. These include: an increase in the level of morbidity, a decrease in the level of education, an increase in the level of unemployment and, as a consequence, an increase in crime and social tension in the society, a decrease in the quality of the human potential, and a decrease in opportunities to attain sustainable development in the Russian Arctic.

The results of a study of different approaches to the problem of assessing income differentiation show the identification of different population strata and groups, which determine the degree of their socio-economic inequality in access to economic benefits and realization of individual life goals.

The research methodology is based on the statistical and analytical method of processing official data of the Federal State Statistics Service (Rosstat) according to the indicators contained in the statistical collections "Regions of Russia." In particular, a comparative analysis between regions of the Arctic zone was carried out using the indicators of average per capita incomes of the population, the distribution of incomes according to the Gini coefficient, the share of employees with a higher educational level, the share of the population under the working age, the number of university students. The construction of graphic models made it possible to assess the degree of differentiation of regions and to distinguish groups of regions according to features characterizing general trends. The time period selected for data evaluation for the study was 2010-2019.

\section{Results}

Primary attention in this study is given to the dynamics of economic development of the Arctic regions in terms of income. Most researchers study regional differentiation through changes in the average per capita income of the population. The Russian statistical database for the constituent entities of the Russian Federation collects indicators of money incomes, presents the structure of income sources, and calculates the average per capita income.

Regional differentiation can be measured by the Gini coefficient, which allows estimating the level of difference between territories according to the indicator in question. The Gini coefficient takes values in the interval from 0 to 1 , and the closer is the value of the coefficient to 1, the higher is the heterogeneity. Use the Gini coefficient we can analyze regional differentiation by money incomes and show the process of 
convergence or divergence of regions according to the degree of stratification of the population depending on the amount of income received.

As a result of the collection and processing of the statistical source data, an array of data was obtained for regions of the Arctic zone for the period 2010-2019, which reflects changes in the dynamics of growth of average per capita incomes. The results are given in Figure 1.

Estimation of average per capita income in the Arctic regions revealed a steady increase in the level of average per capita monetary income, which in general exceeds the average level for Russia at large. To wit, since 2015, the indicator level in the Chukotka (61,704 rubles), Yamalo-Nenets (66,869 rubles), and Nenets (70,924 rubles) Autonomous Districts has been twice higher than the average in Russia $(30,474$ rubles). For the Murmansk Region and the Republic of Sakha, the regional indicator was only slightly higher than the average level in Russia. The rest of the regions are slightly behind the Russian average. The significant difference from the Russia's average is due to the fact that the concealment of income is not such a common practice in the Arctic as it is in Russia overall. And the main source of household income is salaries, which determine the family's ability to meet individual and family needs. It is worth noting the increase in internal differences. Regions rich in natural resources - Chukotka Autonomous District, Yamalo-Nenets Autonomous District, Nenets Autonomous District, are significantly different from other Arctic regions, suggesting that the availability of natural resources is an important factor for the incomes of the population. The lowest average per capita income is found in the Republic of Karelia and the Krasnoyarsk Krai.

The estimation of the average stratification of money incomes in these regions using the Gini coefficient produced a range of values and their changes in the regions for the period 2010 -2019. The lowest level of stratification of population incomes was found in the Republic of Karelia (0.36 in 2010; 0.33 in 2019), which is an Arctic region with a minimum level of growth in average per capita income. The highest Gini coefficient (0.45 in 2010; 0.42 in 2019) was determined for the resource-rich regions - the Nenets and Yamalo-Nenets Autonomous Districts, driving us to the conclusion that there is a greater concentration of financial resources among certain groups of the population there.

In general, it can be noted that there is a tendency for a reduction of income differences between various groups of the population within the regions, but a significant $(2.3 \%)$ increase in interregional differentiation in money incomes.

Anywhere in the world, the person's level of education is considered as a key factor in the social, political, and economic development of the territory. In Russia, this tendency - 


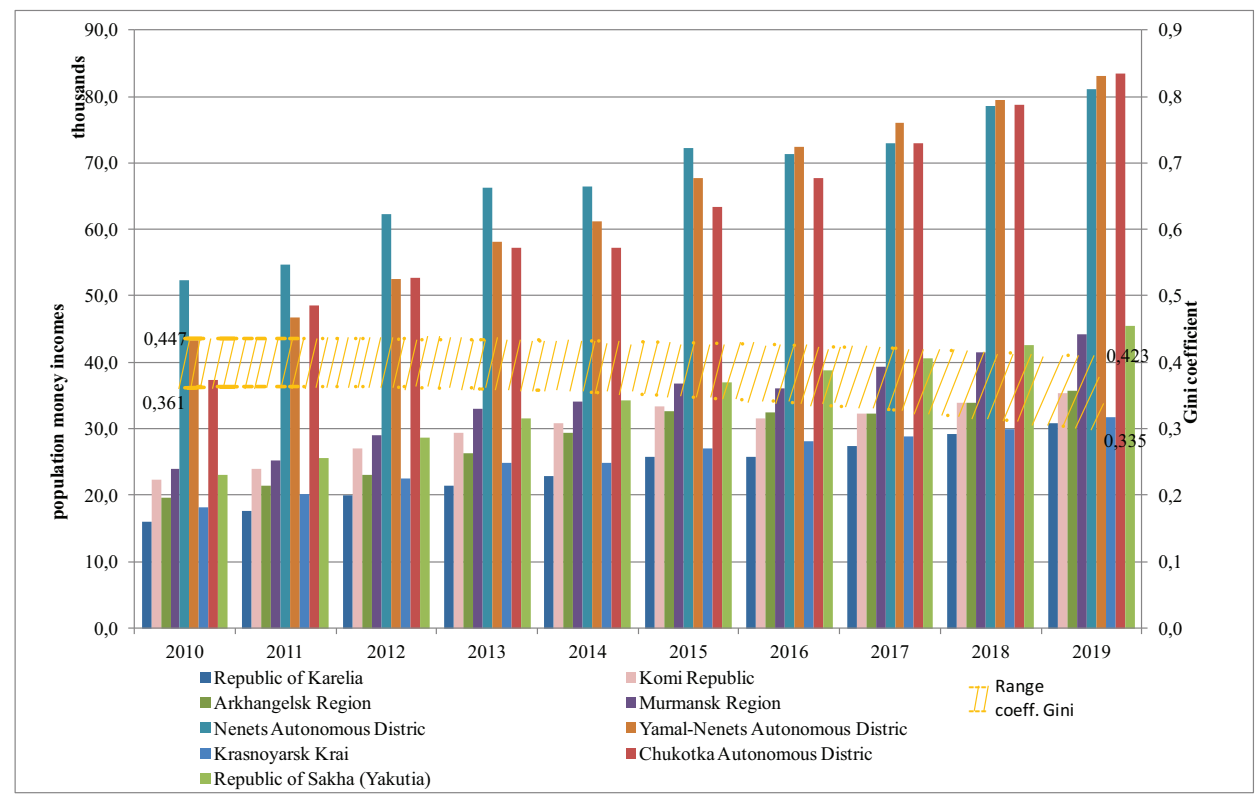

Figure 1: Average per capita incomes in regions of the Arctic zone and the range of their differentiation according to the Gini coefficient in the period from 2010 to 2019.

the influence of educational level on personal income began to manifest itself relatively recently, from the beginning of the 2000s, showing that the return on an individual's investment in education involves a long time lag. The results of sociological studies show that the presence of at least one member with higher education in a family increases the overall level of family income, affects the quality of life, and the level of well-being.

For regions of the Arctic zone, where, on average, the population share with higher education is $23 \%$ of the economically active population, which is higher than in Russia overall (22.8\%), increasing this share is not only a priority but also a strategic task of innovative development of the Arctic economy until 2025.

A comparative analysis of the structure of employment in the period from 2010 to 2019 in the economy of the regions included in the Arctic zone revealed a number of features that can be seen in Figure 2.

In recent years, the share of employees with higher education has increased significantly, by an average of $10 \%$, reaching $30-45 \%$ of the total number of employees. The change in the share of employees with higher education proceeded unevenly over time. In the Nenets Autonomous District, this indicator has increased rapidly since 2014.

Two groups of regions are especially noticeable in terms of population incomes depending on the level of education: Yamalo-Nenets, Chukotsky, Nenets Autonomous Districts and the group represented by the Arkhangelsk, Murmansk Regions and the Republics of Sakha (Yakutia), Komi and Karelia. In the group of autonomous districts, there is a significant differentiation in the growth of incomes, which is due to the 


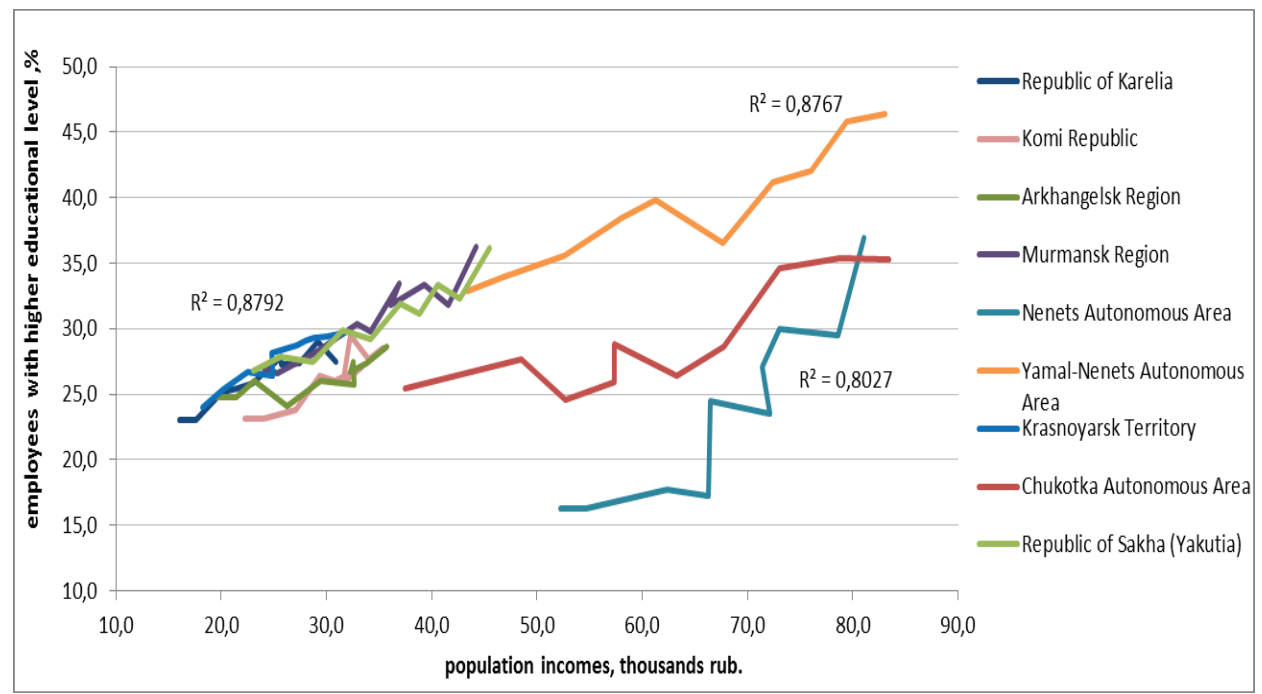

Figure 2: Change in the effect of the share of the employees with higher education on the average per capita income in regions of the Arctic zone from 2010 to 2019.

difference in the salaries of the mining sector employees, and a larger number of mining enterprises in the Yamalo-Nenets Autonomous District.

The share of employees with higher education was found to have an effect on the average per capita income; the correlation coefficient for most regions of the Arctic zone was 0.8-0.87.

\section{Discussion}

In the future, demand in local labor markets will determine changes in the share of employees with higher education in the Arctic regions. It is expected that starting 2021 several tens of thousands of specialists will be required annually in the Arctic. Among them, the number of employees with higher level of education will be one third.

The regions will not be able to satisfy such a demand with their own educational potential. The main limitation in this situation is the demographic factor, with a general trend for out-migration, which applies to a greater extent to the younger generations, who leave the territory with their children, or without starting a family at all. Furthermore, there has lately been only a slight increase in the number of people under working age. Their share in the total population ranges from $18 \%$ to $24.5 \%$. In the coming years, this fact will pre-determine the number of young people willing to receive higher education and enter local labor markets.

Speaking of the dynamics of the number of university students in regions of the Arctic zone, the overall trend is a decrease in their share to less than a half of the level of 
2010. Where the average number of university students per 10,000 people in 2010 was 344, it decreased to 144 by 2019.

Another factor that exacerbates the situation with the regional educational potential is the development level of the educational system in regions of the Artic zone. Currently, universities and colleges in Arctic territories can admit only about 59\% of school graduates as students. Thus, in order to receive education school graduates have to leave their home places for other cities, and most of them do not return after graduation.

\section{Conclusions}

The specific economic factors and the trying climatic and geographic conditions of life in the Arctic tell on incomes and life strategies. In the structure of money incomes, salaries are the main source of income for employees.

Within this study, two groups of regions with significant regional differences in average per capita income were identified, and for a majority of the regions this indicator was higher than the average in Russia. The range of changes in the Gini coefficient across the regions indicates the emerging general trend of decline in income inequality, but the problem of interregional differences both in economic and in social indicators remains acute for the Arctic regions.

A significant differentiation of incomes depending on the level of education has appeared in the modern society: the more educated and qualified a person is, the higher salary he/she can get. It is estimated that the impact of higher education on increasing the money income is high in regions of the Arctic zone. In the future, however, the increase of the share of employees with higher education in the economy of Arctic regions will depend on the region's own ability to build the educational potential among its population despite negative demographic trends - youth out-migration, decrease in the number of university students, and increase in the share of labor migrants.

In order to preserve young human resources and ensure development in the priority areas for the Arctic until 2025, it is important to establish a system of incentives that will attract young people to work in the Arctic, to create the infrastructure for higher education in regions of the Arctic zone, to build the capacities of flagship universities in training personnel for the regional economy, to develop the format of targeted threeparty (organization-applicant-university) training contracts for local school graduates.

The solution to the problems of economic development in the Arctic zone cannot be the same for all regions. In the process of planning and programming the development of this macroregion, one should take into account the specific characteristics revealed 
for the autonomous districts, with their high differentiation in the level of salaries and a low share of their internal human potential with higher education. Special attention could be given to another group of regions, with their unique historically formed directions of social-economic development of the Arctic.

\section{Funding}

The work was funded from the federal budget under state assignment to the Institute of Economics of the Karelian Research Centre of the Russian Academy of Sciences.

\section{References}

[1] Rating of regions by population income 2020. RIA.ru. Date issued: 06.07.2020. Available from: https://ria.ru/20200706/1573773182.html

[2] Cygankova A.A., Romanchenko O.V., Shemetkova O.L. Infrastructure of the Arctic zone of the Russian Federation: State, economic development tools and priority projects. Regional Economy and Management: Electronic Scientific Journal. 2016;4(48). Date issued: 24.11.2016. Available at: https://eee-region.ru/article/4816/

[3] Lazhentsev V. Socio-economic space and territorial development of the north and the Arctic of Russia. Economy of Region. 2018;14(2):353-365.

[4] Berezikov S. Structural shifts in the industry of Arctic regions of Russia. IOP Conference Series: Earth Environment Science. 2019; 302(1). DOI: 10.1088/1755$1315 / 302 / 1 / 012142$

[5] Druzhinin P, Potasheva O. The role of innovation in the economic development of the Northern and Arctic regions. Arctic: Ecology and Economy. 2019;3(35):4-15.

[6] Korchak E.A., Serova N.A., Emelyanova E. E. Human capital of the Arctic: Problems and development prospects. IOP Conference Series: Earth Environment Science. 2019; 302(1). DOI: 10.1088/1755-1315/302/1/012078

[7] Samarina V.P., Samarin A.V., Skufina T.P. The population settlement in Russia's Arctic zone: Facts and trends. IOP Conference Series: Earth Environment Science. 2019; 302(1) DOI: 10.1088/1755-1315/302/1/012081

[8] Zlenko E. Features of the conditions for the formation of monetary incomes of the population and the cost of living in the Arctic zone of Russia. Living Standards of the Population in the Regions of Russia. 2017;1(203):65-75. 
[9] Moroshkina M, Potasheva O. Development of the northern regions in the last decade: The state and priorities of the formation of personnel potential. Drucker's Bulletin. 2020;2(34):285-293.

[10] Atkinson A. On the measurement of inequality. Journal of Economic Theory. 1970;2(3):244-263.

[11] Theil H. Economics and information. Theory Journal Article North-Holland. 1967;18(3):309-328.

[12] Gini C. On the measure of concentration with special reference to income and statistics. Colorado College Publication General Series. 1936;208:73-79.

[13] Malkina M. Dynamics and factors of intraregional and interregional income differentiation of the population. Spatial Economics. 2014;3:44-66.

[14] Pinkovetskaya Y. Assessment of the convergence of small enterprise performance indicators between the regions of the Russian Federation. Bulletin of the Pacific State University of Economics Issue. 2013;2(66):20-33.

[15] Roshchina Y. Differentiation of income and education in Russia. Voprosy Obrazovaniya. 2005;4:274-296.

[16] Gordievich T, Ruzanov P. The standard of living and the dynamics of income of the population. Omsk Scientific Bulletin. Series «Society. History. Modernity». 2020;5(1):127-135.

[17] Gataullin R. Patterns of formation of interregional differences in income. Bulletin of Eurasian Science. 2012;4(13):1-9.

[18] Korchak EA. Threats to the sustainable development of the Russian Arctic: Poverty. Arktika i Sever [Arctic and North]. 2020;40:41-56. 